\title{
PENYULUHAN DAN PELATIHAN PEMBUATAN SABUN CUCI PIRING \\ ${ }^{1}$ Edi Supriyadi, ${ }^{2}$ Rully Nur Dewanti, ${ }^{3}$ Taufik, ${ }^{4}$ Junaedi, ${ }^{5}$ Soleh Sofyan \\ Dosen Teknik Industri Universitas Pamulang \\ Email:1dosen00905@unpam.ac.id
}

\begin{abstract}
ABSTRAK
Peningkatan kesejahteraan sosial dapat dilakukan dengan berbagai pendekatan, dengan memberdayakan masyarakat. Memberdayakan ibu-ibu PKK RT 05 di Tanah Baru Depok melalui pelatihan dan pendampingan produksi sabun cuci piring. Kegiatan ini dilakukan dalam rangka meningkatkan sumber daya manusia yang mampu mengandalkan kekuatannya sendiri. Tujuan dan target spesifik yang ingin dicapai dalam kegiatan ini adalah ibu-ibu PKK RT 05 tertarik dan termotivasi untuk berwirausaha, membentuk kelompok anggota PKK yang menjadi mandiri secara ekonomi dengan memproduksi sabun cuci piring, serta merealisasikan PKK RT 05 lebih kuat, lebih produktif, kreatif, dan responsif. Untuk mencapai tujuan ini, tim pengabdian masyarakat Program Studi Teknik Industri telah memberikan konseling, pelatihan dan bantuan ibu-ibu PKK dalam memproduksi sabun cuci piring. Ibu-ibu PKK diberikan pengetahuan tentang pengusaha dan peluang bisnis berbasis rumah, serta prinsip-prinsip dasar produksi. Ibu-ibu PKK juga diberikan pelatihan tentang cara membuat sabun cuci piring, serta pengemasan produk dan teknik pemasaran.
\end{abstract}

\section{Kata Kunci : Sabun, Konseling, Pelatihan, Produksi}

\section{PENDAHULUAN}

Sabun adalah bahan yang digunakan untuk mencuci, baik pakaian, perabotan, badan dan lain-lain yang terbuat dari campuran alkali (natrium atau kalium hidroksida) dan trigliserida dari asam lemak rantai karbon C16 (Zulkifli dan Estiasih, 2014) melalui reaksi saponifikasi atau disebut juga reaksi penyabunan pada suhu $80-100 \mathrm{oC}$. Dalam proses ini asam lemak akan terhidrolisa oleh basa membentuk gliserin dan sabun mentah.

Sabun dapat menghilangkan kotoran dan minyak karena struktur kimia sabun terdiri dari bagian yang bersifat hidrofil pada rantai ionnya dan bersifat hidrofobik pada rantai karbonnya. Karena adanya rantai hidrokarbon, sebuah molekul sabun secara keseluruhan tidaklah benar-benar larut dalam air. Namun sabun mudah tersuspensi dalam air karena membentuk misel (micelles), yakni segerombolan (50-150) molekul yang rantai hidrokarbonnya mengelompok dengan ujung-ujung ionnya yang menghadap ke air. Dalam menghilangkan kotoran dan minyak, bagian yang bersifat hidrofobik pada sabun akan larut dalam minyak dan mengepung kotoran minyak, sedangkan bagian hidrofilik akan terlepas dari permukaan yang dibersihkan dan terdispersi dalam air sehingga dapat dicuci. 
Keberdayaan perempuan di bidang ekonomi adalah salah satu indikator meningkatnya kesejahteraan. Saat perempuan menjadi kaum terdidik, mempunyai hak-hak kepemilikan dan bebas untuk bekerja di luar rumah serta mempunyai pendapatan mandiri, inilah tanda kesejahteraan rumah tangga meningkat. Lebih dari itu, perempuan juga mempunyai andil besar dalam kegiatan penanggulangan kemiskinan melalui pemberdayaan masyarakat dan kelompok. Salah satu buktinya, bahwa perempuan dapat meningkatkan kesejahteraan keluarganya dengan melakukan kegiatan usaha produktif rumah tangga.

\section{METODE PELAKSANAAN KEGIATAN}

\section{Kerangka Pemecahan Masalah}

Sabun sebagai salah satu kebutuhan utama untuk mendapatkan standar kebersihan yang baik dalam kehidupan sehari-hari termasuk dalam kebutuhan pokok, tetapi sabun tidak termasuk dalam kelompok kebutuhan primer. Pemenuhan akan sabun seringkali dianggap sebagai kebutuhan sekunder, karena kebutuhan primer (sandang, pangan, papan) merupakan kebutuhan yang wajib untuk dipenuhi setiap hari. Konsumsi sabun yang terus menerus setiap harinya, menyebabkan kebutuhan pengadaan sabun yang membutuhkan biaya yang tidak sedikit.

Dalam menjalankan usaha pembuatan sabun yang selama ini digunakan untuk mencuci piring adalah sabun colek dengan harga $\mathrm{Rp} 2.600$,- per sachet per hari. Penyediaan sabun sachet untuk 1 bulan membutuhkan biaya sebanyak Rp 52.000,-. Hal ini menunjukkan bahwa masyarakat harus menyediakan dana minimal Rp 52.000,- per bulan untuk pengadaan sabun yang diperlukan untuk membersihkan peralatan memasak.

\section{Realisasi Pemecahan Masalah}

PKK RT 05 merupakan salah satu wadah organisasi perempuan di RW 09 desa Tanah Baru Depok. Latar belakang pendidikan ibu-ibu PKK tersebut beragam (lulusan SLTA dan perguruan tinggi) dan sebagian besar adalah ibu rumah tangga dengan keadaan ekonomi keluarga yang berada pada ekonomi menengah ke bawah. Mencari pekerjaan sudah semakin sulit untuk ibu-ibu ini, sedangkan kebutuhan mencukupi kebutuhan sehari-hari mengharuskan pengeluaran yang semakin meningkat. Walaupun demikian, diyakini sangat banyak kemampuan yang dimiliki kaum ibu- ibu tersebut dalam meningkatkan kesejahteraan keluarga.

Pemberdayaan Ibu-ibu PKK sebagai anggota masyarakat dan masih tergolong sebagai tenaga kerja produktif sangat penting dilakukan, bertujuan untuk menumbuhkan kesadaran dan kemandirian dalam berusaha, sekaligus memperluas lapangan kerja guna meningkatkan pendapatan keluarga dalam usaha mencapai keluarga yang bahagia dan sejahtera. Dalam kaitannya dengan upaya untuk membina dan mengembangkan potensi keluarga dan daerah, dapat dilakukan melalui berbagai alternatif kegiatan, diantaranya berupa pelatihan pembuatan Sabun dan deterjen. Sabun dan deterjen merupakan sebuah 
komoditas yang tidak bisa dilepaskan dari kebutuhan rumah tangga dewasa ini. Alat produksi yang digunakan dalam proses pembuatannya tidaklah banyak dan rumit layaknya pabrik-pabrik besar. Alternatif ini dipilih mengingat ibu-ibu kader PKK di wilayah ini sangat membutuhkan pengetahuan dan keterampilan yang dapat dijadikan bekal untuk merintis usaha dan mereka sebelumnya belum pernah mendapatkan latihan keterampilan ini. Peluang pemasarannya sangat terbuka lebar karena semakin menjamurnya usaha laundry disekitar daerah Tanah Baru Depok. Disamping itu kegiatan yang ditawarkan ini dapat dikerjakan dirumah sehingga ibu-ibu akan lebih mudah menyesuaikan dengan peran domestiknya sebagai ibu rumah tangga.

Pembinaan ini diharapkan dapat melengkapi wawasan pengetahuan dan keterampilan ibu-ibu PKK dalam berbagai segi kehidupan keluarga, yang dapat digunakan untuk menunjukkan eksistensi dirinya, turut memenuhi kebutuhan keluarganya sehingga dengan melakukan sendiri akan menghemat keuangan keluarga dan dapat dijadikan bekal untuk membuka usaha yang pada akhirnya dapat menambah penghasilan keluarga.

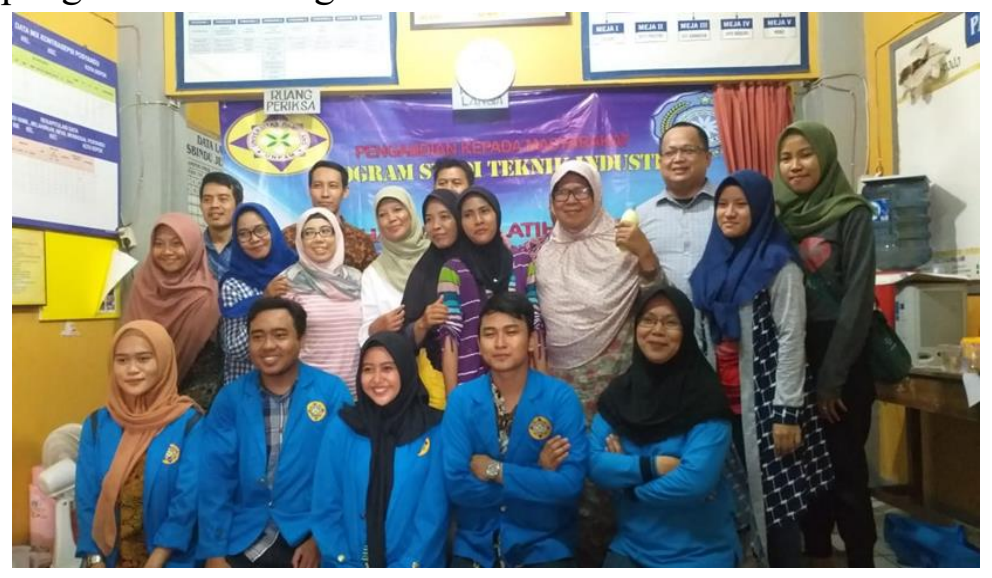

Gambar 1. Foto Bersama Ibu - Ibu PKK

\section{Khalayak Sasaran}

Kegiatan pengabdian ini dilakukan di Rukun Warga Tanah Baru Depok, dengan Ibu-Ibu PKK RT 05. Kegiatan yang dilakukan adalah sebagai berikut :

a. Koordinasi dengan pihak-pihak yang terkait

Koordinasi tim pengabdian kepada masyarakat Program Studi Teknik Industri dilakukan dengan mitra yaitu Ketua PKK RT 05 Tanah Baru Depok. Pada kegiatan ini tim pengabdian dan mitra membahas tentang kegiatan pengabdian kepada masyarakat yang akan dilaksanakan, tempat dan waktu pelaksanaan penyuluhan dan pelatihan. Pada pertemuan ini ada beberapa hal yang disepakati, yaitu kegiatan pengabdian kepada masyarakat, waktu dan tempat pelaksanaan penyuluhan pelatihan pembuatan sabun cuci piring.

b. Persiapan penyuluhan dan pelatihan

Persiapan kegiatan ini berupa penentuan formula sabun cuci piring, pembuatan modul penyuluhan dan pelatihan. Modul pelatihan berisi tentang 
bahan-bahan, alat-alat dan cara pembuatan sabun cuci piring. Pada persiapan pelatihan, Tim pengabdian kepada masyarakat melakukan uji coba resep pembuatan produk sabun cuci piring, sehingga didapatkan komposisi yang tepat dan memberikan hasil optimal.

\section{Tempat dan Waktu}

Penyuluhan diadakan dibalai rukun warga, dengan dihadiri oleh ibu- ibu PKK RT 05. Penyuluhan di PKK RT 05 dilaksanakan hari minggu, 27 Oktober 2019. Materi yang disampaikan adalah Penyuluhan dan Pelatihan Pembuatan Sabun Cuci Piring.

\section{Metode Kegiatan}

Metode pelaksanaan kegiatan yang akan dilakukan untuk mengatasi permasalahan adalah sebagai berikut :

a. Penyuluhan.

Materi penyuluhan adalah pelatihan pembuatan sabun cuci piring. Tujuan penyuluhan ini adalah memberikan ilmu dan wawasan baru kepada ibu-ibu PKK tentang wirausaha dan peluang usaha rumahan, sehingga terbuka pikiran serta tumbuh minat dan motivasi dalam diri mereka untuk berwirausaha. Disamping itu juga diberikan materi tentang prinsip dasar pembuatan, bertujuan agar mitra mengetahui cara pembuatan. Penyuluhan ini disampaikan dalam bentuk ceramah dan tanya jawab kepada peserta.

b. Pelatihan

Materi pelatihan adalah cara pembuatan sabun cuci piring. Kegiatan ini bertujuan untuk memberikan keterampilan tentang cara pembuatan sabun cuci piring. Pelatihan tersebut disampaikan dalam bentuk ceramah yang dilanjutkan dengan eksperimen langsung dan tanya jawab tentang cara pembuatan produk tersebut. Pelatihan dilaksanakan sampai semua peserta mahir mempraktekkan sendiri.

c. Prosedur kegiatan

Kegiatan pengabdian ini meliputi: 1) Koordinasi dengan mitra, terkait dengan penyusunan jadwal kegiatan; 2) Persiapan penyuluhan dan pelatihan; 3) Penyuluhan tentang prinsip dasar pembuatan sabun cuci piring; 4) Pelatihan cara pembuatan sabun cuci piring; dan 5) Pembinaan pasca kegiatan.

d. Partisipasi Mitra

Partisipasi mitra dalam pelaksanaan kegiatan ini adalah partisipasi aktif, dari mulai perencanaan kegiatan, penyusunan jadwal penyuluhan dan pelatihan. Partisipasi mitra akan dievaluasi. Evaluasi akan dilaksanakan selama dan setelah pelaksanaan kegiatan penyuluhan dan pelatihan. Selama pelaksanaan kegiatan dilakukan evaluasi dengan metode pengamatan langsung oleh Tim Pengabdian. Sedangkan setelah pelaksanaan kegiatan dilakukan evaluasi dengan metode pengamatan terhadap hasil kegiatan. Kriteria evaluasi meliputi kasadaran dan antusiasme peserta penyuluhan dan pelatihan dalam mengikuti kegiatan serta tingkat kemahiran peserta dalam mempraktekkan sendiri pembuatan sabun cuci piring yang telah diajarkan. 


\section{HASIL DAN PEMBAHASAN}

Kegiatan pengabdian ini dilakukan di Rukun Warga Tanah Baru Depok, dengan Ibu-Ibu PKK RT 05. Kegiatan yang dilakukan adalah sebagai berikut :

a) Koordinasi dengan pihak-pihak yang terkait

Koordinasi tim pengabdian kepada masyarakat Program Studi Teknik Industri dilakukan dengan mitra yaitu Ketua PKK RT 05 Tanah Baru Depok. Pada kegiatan ini tim pengabdian dan mitra membahas tentang kegiatan pengabdian kepada masyarakat yang akan dilaksanakan, tempat dan waktu pelaksanaan penyuluhan dan pelatihan. Pada pertemuan ini ada beberapa hal yang disepakati, yaitu kegiatan pengabdian kepada masyarakat, waktu dan tempat pelaksanaan penyuluhan pelatihan pembuatan sabun cuci piring.

b) Persiapan penyuluhan dan pelatihan

Persiapan kegiatan ini berupa penentuan formula sabun cuci piring, pembuatan modul penyuluhan dan pelatihan. Modul pelatihan berisi tentang bahan-bahan, alat-alat dan cara pembuatan sabun cuci piring. Pada persiapan pelatihan, Tim pengabdian kepada masyarakat melakukan uji coba resep pembuatan produk sabun cuci piring, sehingga didapatkan komposisi yang tepat dan memberikan hasil optimal.

Formula sabun dan deterjen yang akan diproduksi adalah sebagai berikut :

1. Sabun cuci piring, dengan komposisi untuk 1liter :

a. Texapon $100 \mathrm{~g}$

b. Sodium sulfat $50 \mathrm{~g}$

c. Comperland $10 \mathrm{~g}$

d. Foam booster $50 \mathrm{~g}$

e. EDTA $1 \mathrm{~g}$

f. Asam sitrat $10 \mathrm{~g}$

g. Fixative:Parfum (1:2) $5 \mathrm{cc}$

h. Pewarna

i. Air $900 \mathrm{cc}$

2. Pembelian alat dan bahan

Alat dan bahan yang dibutuhkan pada pelatihan pembuatan sabun cuci piring, antara lain baskom kecil, pengaduk kayu, sendok, gelas ukur, masker, sarung tangan, kain lap, timbangan, wadah plastik kecil, wadah plastik besar, ayakan, corong, botol plastik, plastik kemasan, sealer plastik, label.

Bahan yang diperlukan antara lain: SLS, sodium sulfat, STPP, soda abu, CMC, texapon, compeland, sodium khlorida, foam boaster, fixatif, asam sitrat, parfum, pewarna, EDTA, supersoft, metanol, aquades.

c) Pelaksanaan Pelatihan

Pelatihan diberikan dalam bentuk ceramah yang dilanjutkan dengan eksperimen langsung dan tanya jawab. Praktek cara pembuatan pembuatan sabun cuci piring. Ibu-ibu PKK dibagi dalam beberapa kelompok, kemudian 
dengan dibimbing Tim pengabdian kepada masyarakat mempraktekkan sendiri pembuatan produk tersebut. Pelatihan dilaksanakan sampai semua peserta mahir mempraktekkan sendiri.

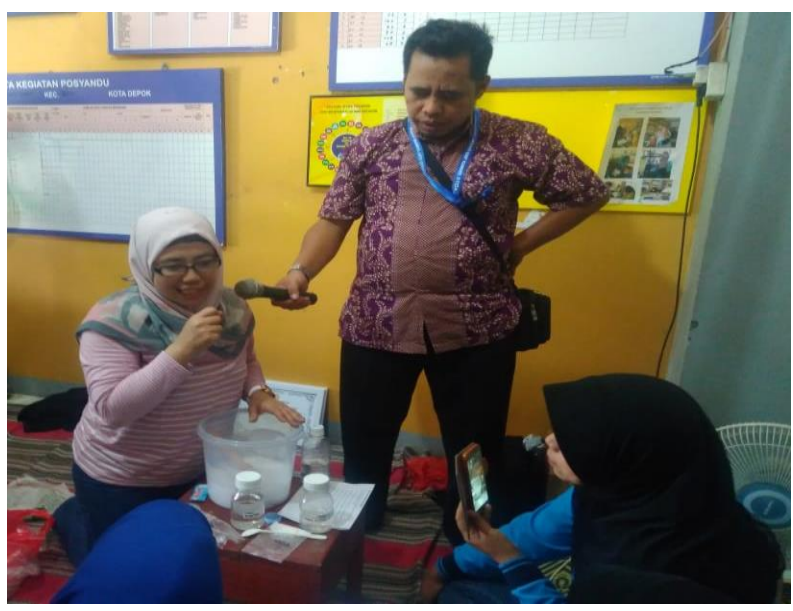

Gambar 2. Pelatihan Peserta Ibu PKK

\section{KESIMPULAN DAN SARAN}

Dalam pelatihan pembuatan sabun cuci piring dapat diambil kesimpulan bahwa kegiatan dapat berjalan dengan lancar sesuai dengan yang direncanakan. Kegiatan ini dapat meningkatkan pengetahuan dan ketrampilan dalam pembuatan sabun cuci piring yang dapat dikonsumsi pribadi maupun dikomersilkan.

\section{DAFTAR PUSTAKA}

A Sobarna, S Hambali, S Sutiswo, D Sunarsi. (2020). The influence learning used ABC run exercise on the sprint capabilities. Jurnal Konseling dan Pendidikan 8 (2), 67-71

A Sudarsono, D Sunarsi. (2020). Pengaruh Kualitas Pelayanan Dan Varian Produk Terhadap Keputusan Pembelian Pada Laboratorium Klinik Kimia FarmaBintaro. Value: Jurnal Manajemen dan Akuntansi 15 (1), 16-26

Anonim, Sabun dan deterjen, 2012, http://apikimia.blogspot.com/, diakses 10 Oktober 2019;

Anonim, Sabun dan deterjen, http://www.chem-is-try.org/materi_kimia/kimialingkungan/pencemaran_lingkungan/sabun-dan-deterjen/,diakses $\quad 10$ Oktober 2019;

Apriyani, D. 2013. Formulasi Sediaan Sabun Mandi Cair Minyak Atsiri Jeruk Nipis (Citrus aurantifolia) Dengan Cocamid Dea Sebagai Surfaktan. Universitas Muhammadiyah Surakarta (Doctoral dissertation);

D Sunarsi. (2014). Pengaruh Gaya Kepemimpinan, Motivasi dan Disiplin Kerja Terhadap Kinerja Pendidik. Universitas Pamulang

D Sunarsi. (2020). Kepemimpinan Bisnis Strategik. Kota Serang: Desanta Muliavisitama 
Gumilar, I., Sunarsi, D. (2020). Comparison of financial performance in banking with high car and low car (Study of banks approved in the kompas 100 index for the period 2013-2017). International Journal of Psychosocial Rehabilitation. Volume 24 - Issue 7

Maddinsyah, A., Sunarsi, D., Hermawati, R., Pranoto. (2020). Analysis of location selection effect on the user decision that influcence the success of the service business of micro, small and medium enterprise (MSME) in bandung timur region. International Journal of Advanced Science and Technology. Vol. 29 No. 06

Purwanti, P., Sarwani, S., \& Sunarsi, D. (2020). Pengaruh Inovasi Produk Dan Brand Awareness Terhadap Keputusan Pembelian Konsumen Pada Pt. Unilever Indonesia. Inovasi, 7(1), 24-31.

Soedardjo, S., Darlis, D. L., Sudarmin, S. D., \& Sarwani, S. (1995). Evaluasi Kualitatif Sistem Mikroergonomik Panel Pengendaliin-Pile LOOP RSGGAS. Prosiding Seminarke-3 Teknologi Dan Keselamatan PLTN serta Fasilitas Nuklir.

Sunarsi, D., \& Asmalah, L. (2018). Pelatihan Manajemen Pengembangan Diri Bagi Penerima Beasiswa RZIS UGM Dan Dompet Shalahuddin Jogjakarta. Jurnal Pengabdian Dharma Laksana, 1(1), 51-60.

Sunarsi, D., Kusjono, G., \& Nuryana, I. (2019). Pelatihan Manajemen Penguasaan Kelas Dan Pembuatan Bahan Ajar Bagi Tenaga Pengajar Sukarela Taman Belajar Kreatif Mekarsari. Jurnal Pengabdian Dharma Laksana, 2(1), 41-44.

Sunarsi, D., Kustini, E., Lutfi, A. M., Fauzi, R. D., \& Noryani, N. (2019). Penyuluhan Wirausaha Home Industry Untuk Meningkatkan Ekonomi Keluarga Dengan Daur Ulang Barang Bekas. BAKTIMAS: Jurnal Pengabdian pada Masyarakat, 1(4), 188-193.

Suroso, S., Sarwani, S., Suwoto, S. W., \& Putut Hery Setiawan, P. H. S. (1999). Pengaruh Neutron Terhadap Struktur Mikro Topas. In Prosiding Seminar Hasil Penelitian Prsg. PRSG-BATAN.

Susanto, S., Sarwani, S., \& Afandi, S. (2018). Analisis Kinerja Keuangan Untuk Mengetahui Tingkat Kesehatan, Pertumbuhan Dan Prospek Usaha Pada Unit Usaha Koperasi (Studi Kasus Koperasi Awak Pesawat Garuda Indonesia di Tangerang). INOVASI, 1(1).

Sutrisno, S., Sarwani, S., Ariyawan Sunardi, A. S., \& Asnul Sufmawan, A. S. (2009). Analisis Iradiasi Target Tungsten Di Reaktor Serba Guna-Ga Siwabessy. In Prosiding Seminar Nasional Teknologi Dan Aplikasi Reaktor Nuklir. PRSG-BATAN.

Suwoto, S., Sarwani, S., Rohidi, R., \& Saleh Hartaman, S. H. (1998). Optlmasi Iradiasi

Tanjung, D.A., 2017. Pelatihan Pembuatan Sabun Cair dan Shampoo Pencuci Mobil. Jurnal Prodikmas Hasil Pengabdian Masyarakat. 2(1):41-45.

Zulkifli, M. \& Estiasih. 2014. Sabun dari Distilat Asam Lemak Minyak Sawit. Jurnal Pangan dan Agroindustri. 2 (4):170-177. 